\title{
A small-sample survey of dry eye symptoms using the Ocular Surface Disease Index
}

\section{WDH Gillan*}

\author{
Department of Optometry, University of Johannesburg, PO Box 524, Auckland Park, 2006 South \\ Africa
}

$<$ wgillan@uj.ac.za>

Received 7 July 2009; revised version accepted 27 October 2009

\section{Introduction}

"Dry Eye" is an all-encompassing term used to label a number of disease states that result in numerous visits to eye-care practitioners ${ }^{1}$. Lemp ${ }^{1}$ defined dry eye as: "dry eye is a disorder of the tear film due to tear deficiency or excessive evaporation which causes damage to the inter-palpebral ocular surface and is associated with symptoms of ocular discomfort". A more recent definition of dry eye is: "dry eye is a multifactorial disease of the tears and ocular surface that results in symptoms of discomfort, visual disturbance and tear film instability with potential damage to the ocular surface. It is accompanied by increased osmolarity of the tear film and inflammation of the ocular surface" ${ }^{2}$. The exact cause of symptoms in what might, or might not, be a state of dry eye is not known. However, the basis of symptomology could be considered to be dependent on etiologic mechanisms and the various responses of individuals to dry eye thera$\mathrm{py}^{2}$. It is well documented that little correlation exists between the dry eye symptoms that patients present with and objective signs of ocular compromise ${ }^{1,3-7}$. It becomes difficult to make accurate diagnostic decisions when one is faced with a symptomatic patient who has no, or very little physical change to observe (and of course the opposite is true as well). It has also been suggested that questioning patients regarding dry eye symptoms has more diagnostic value than clinical testing does ${ }^{5}$.

It has been stated previously that "virtually no data in reference to risk factors for the development of dry eye" exists ${ }^{1}$. The need for studies addressing the influence of lifestyle, dietary effects and other risk factors for dry eye has been emphasized ${ }^{3}$. Several studies investigating the risk factors involved in dry eye have been published with risk factors including: older age, being female, being post-menopausal, wearing contact lenses, rheumatoid arthritis, smoking, caffeine use and medications (antihistamines, diuretics and beta-blockers $)^{3,8}$. Dry eye has been shown to have a negative impact on the quality of everyday life and to result in loss of productivity ${ }^{9}$. Miljanović et a ${ }^{10}$ have shown that subjects with dry eye are more likely to develop problems reading, carrying out professional work (what ever that means), using a computer, watching TV and driving.

Numerous studies have been conducted on the prevalence of dry eye syndrome. Prevalence varies between $0.39 \%$ and $33.7 \%$ of various research populations $^{2,8,11-14}$. In a questionnaire based approach Doughty et $a l^{15}$ mailed the "Canada dry eye epidemiology study" (CANDEES) questionnaire to all optometric practices in Canada requesting the optometrist to have 30 non-selected patients complete the questionnaire. A total of 13517 questionnaires were returned for analysis (a total of 86160 were mailed). The results of this study showed that approximately $25 \%$ of patients who completed the questionnaire had some level of dry eye symptoms. Severe symptoms were reported by 1 in 225 patients. In another study Ellwein and Urato ${ }^{16}$ determined that the dry eye case incidence per 100 fee-for-service Medicare clients increased by approximately 55\% between 1991 and 
1998. An estimated 4.3 million people in the USA older than 65 years of age suffer from the symptoms of dry eye either often or all of the time ${ }^{17}$. It would seem that dry eye symptoms are a problem for large numbers of people.

Questionnaires are a common tool that are employed to determine the prevalence of dry eye in clinical research, screenings, to assess the effects of treatment and to grade levels of disease severity ${ }^{3,5,7,12,18-21}$. Questionnaires might also have more value in the diagnosis of dry eye than testing for dry eye ${ }^{5}$. The Ocular Surface Disease Index (OSDI) is one such questionnaire that was developed by the Outcomes Research Group at Allergan $^{22}$. The OSDI consists of twelve questions and is designed to provide a quick indication of the symptoms that are consistent with dry eye disease. The OSDI can also be used to grade the severity of dry eye disease and has been accepted by the Food and Drug Administration for use in clinical trials ${ }^{21}$. The validity and reliability of the OSDI have been assessed and it has been found to provide good to excellent reliability, validity, sensitivity and specificity for dry eyes ${ }^{22,23}$.

The aim of this study is to investigate the occurrence and severity of dry eye symptoms among a small sample of individuals using the OSDI.

\section{Method}

Third and fourth year optometry students at the University of Johannesburg, staff in the department of Optometry and family members of staff were asked to voluntarily complete the OSDI questionnaire. Each volunteer received a copy of the OSDI questionnaire and was also asked to indicate their age, gender, whether they were contact lens wearers and whether they were taking any medication (and what medication if relevant). No form of identification was expected from participants.

The OSDI includes a scoring system so that one is able to determine the level of severity of dry eye symptoms. A scale of 0 to 100 is used in assessment with higher scores indicating greater severity of disease. The twelve questions of the OSDI are grouped into three sections. The sections assess: presence of symptoms over the last week, how performance of tasks like reading and driving are affected by symptoms and presence of discomfort over the last week. Each question has a scale of 0 to 4 , indicating increasing severity ( 0 : none of the time to 4 : all of the time). Each section's score is added to give a sum of scores for all questions answered. The total number of questions answered (out of twelve) is also determined (sections two and three allow for the participant to indicate "not applicable"). Readers are able to find the OSDI and the scoring information at: www. restasisprofessional.com. The score for each participant's questionnaire was determined according to the instructions included with the OSDI. A score can be determined for each participant's OSDI using the following formula:

$$
\text { OSDI }=\frac{\text { sum of scores } x 25}{\text { number of questions answered }}
$$

A color-graded scoring chart is provided whereby the investigator can determine the level of dry eye disease for each participant (from normal to severe). An OSDI score was determined and then the color-graded chart was used to categorize each individual in this particular sample.

\section{Results}

A total of 112 individuals completed the OSDI questionnaire. Eighty eight individuals were female and 24 were male, with ages ranging from 18 to 80 years of age. The total sample of subjects was then arbitrarily divided into those aged below 40 and those above 40 years of age. The division of the sample into two age groups was done because it has been shown that age seems to play a role in the prevalence of symptoms of dry eye $e^{3,4,17}$. Table 1 shows the details of the subject numbers, gender and age-related numbers.

Table 1. Subject numbers (and percentages) for the groups below $40(<40)$ and above $40(>40)$ years of age are shown. Male and female subjects $(n=112)$ are indicated ( $\mathrm{M}$ and F respectively). Percentages have been rounded off and are approximate.

\begin{tabular}{|c|c|c|c|}
\hline \multicolumn{2}{|c|}{$<40$ years } & \multicolumn{2}{c|}{$>40$ years } \\
\hline $\mathrm{M}$ & $\mathrm{F}$ & $\mathrm{M}$ & $\mathrm{F}$ \\
\hline $17 / 94(18 \%)$ & $77 / 94(82 \%)$ & $7 / 18(39 \%)$ & $11 / 18(61 \%)$ \\
\hline
\end{tabular}


The distribution of subjects according to age and gender are skewed as a result of the large number of female students in the study sample (students studying optometry at the University of Johannesburg are predominantly female).

Table 2 shows the numbers of subjects who present with a level of, at least, mild dry eye symptoms. Of the "under 40" year old group a total of 61 subjects $(65 \%)$ presented with at least mild dry eye symptoms while the "over 40 " year old group had a total of 11 (61\%) subjects with at least mild dry eye symptoms. Of both age groups a grand total of 72 subjects had at least mild dry eye $(64 \%)$. The details regarding gender effects can be seen in Table 2 .

Table 2. Subject numbers (and percentages) presenting with a level of at least mild dry eye. Subjects are grouped arbitrarily into below 40 years of age and above 40 years of age. $M$ and $\mathrm{F}$ indicate male and female subjects respectively. Percentages have been rounded off and are approximate.

\section{Discussion}

The results of this study show that $64 \%(72 / 112)$ of the sample have at least mild dry eye symptoms. Compared with other studies investigating the prevalence of dry eye symptoms $2,8,11-14$ where the prevalence varies between $0.39 \%$ and $33.7 \%$, this study reveals a much higher prevalence of dry eye symptoms. It is not clear why such a large number of subjects have symptoms. Possible explanations for the high incidence of symptoms could be the fact that the study was done in Johannesburg where the humidity (relatively low?) and altitude might play some role. Of the $<40$ year old group $28 \%$ (26/94) had moderate to severe dry eye while the $>40$ year old group had $33 \%(6 / 18)$ of subjects with moderate to severe dry eye. In another study ${ }^{15}$ one-in-225 subjects reported having severe dry eye symptoms while the results of this study show that four-in-112 subjects report se-

\begin{tabular}{|c|c|c|c|c|c|c|}
\hline \multicolumn{3}{|c|}{$<40$ years } & \multicolumn{4}{|c|}{$>40$ years } \\
\hline $\mathrm{M}$ & $\mathrm{F}$ & Total & $\mathrm{M}$ & $\mathrm{F}$ & Total & Grand Total \\
\hline $12 / 17(71 \%)$ & $49 / 77(64 \%)$ & $61 / 94(65 \%)$ & $4 / 7(57 \%)$ & $7 / 11(64 \%)$ & $11 / 18(61 \%)$ & $72 / 112(64 \%)$ \\
\hline
\end{tabular}

Of the "under 40 " year old group, a total of 26 subjects (28\%) presented with moderate or severe dry eye symptoms while $6(33 \%)$ of the "over 40 " year old group could be classified as having moderate or severe dry eye symptoms. Table 3 gives the details of subject numbers falling into the various categories of dry eye. Of the total group of subjects $(n=112)$ four had severe dry eye symptoms, three of whom were in the "under 40" year old group (see Table 3).

Table 3. Numbers and percentages of subjects falling into the various levels of dry eye. $\mathrm{N}$ indicates normal, Mi: mild dry eye, M: moderate dry eye and S: severe dry eye. Percentages have been rounded off and are approximate. vere dry eye. One of the subjects who reported severe dry eye was on medication for seasonal allergies (Zaditen) which has dry eye as a side-effect ${ }^{25}$.

Although the aim of this study was to investigate the prevalence of symptoms of dry eye, some other aspects of the information gathered are interesting. Of the subjects in the $<40$ year old group who had at least mild dry eye symptoms, 33\% (20/61) were soft contact lens wearers. Contact lens related dry eye is well documented $^{1,2,13,26}$ and it is possible that the majority of subjects who wear contact lenses and who also had at least mild dry eye symptoms might well not have symptoms if they were not contact lens wearers. No

\begin{tabular}{|c|c|c|c|c|c|c|c|c|c|c|c|c|c|c|c|c|}
\hline \multirow[t]{4}{*}{ Subjects } & \multicolumn{8}{|c|}{$<40$ years } & \multicolumn{8}{|c|}{$>40$ years } \\
\hline & \multicolumn{4}{|c|}{ M } & \multicolumn{4}{|c|}{$\mathrm{F}$} & \multicolumn{4}{|c|}{$\mathrm{M}$} & \multicolumn{4}{|c|}{$\mathrm{F}$} \\
\hline & $\mathrm{N}$ & $\mathrm{Mi}$ & $\mathrm{M}$ & $\mathrm{S}$ & $\mathrm{N}$ & Mi & M & $\mathrm{S}$ & $\mathrm{N}$ & Mi & $\mathrm{M}$ & $\mathrm{S}$ & $\mathrm{N}$ & Mi & $\mathrm{M}$ & $\mathrm{S}$ \\
\hline & 5 & 4 & 7 & 1 & 28 & 31 & 16 & 2 & 3 & 3 & 1 & 0 & 4 & 2 & 4 & 1 \\
\hline Percent & 29 & 23 & 41 & 6 & 36 & 40 & 21 & 2 & 43 & 43 & 14 & 0 & 36 & 18 & 36 & 9 \\
\hline
\end{tabular}


subjects in the $>40$ year old group wore contact lenses. $15 \%(9 / 61)$ of the subjects who had at least mild dry eye symptoms in the $<40$ year old group were taking medications (oral contraception, roaccutane, flu medications) while none of the $>40$ year old group were taking medications with dry eye listed as a side effect $^{25}$

Limitations of this study include: the greater number of young female subjects, the small number of subjects in the $>40$ year old group, and the inclusion of contact lens wearers and those taking medication. Future studies need to be conducted where only subjects with no related contra-indications are included. An effort would need to be made to ensure that subject numbers are more evenly spread amongst male/female and young/old subjects.

The aim of this study was to investigate the prevalence of dry eye symptoms in a small group of subjects. The results have shown that a large percentage of the subjects have at least mild dry eye symptoms.

\section{References}

1. Lemp MA. Report of the National Eye Institute/industry workshop on clinical trials in dry eye. CLAO Jnl 199521 221-232.

2. Lemp MA (chairman). The definition and classification of dry eye disease: report of the definition and classification subcommittee of the international dry eye workshop. Oc Surf 20075 75-93.

3. Smith JA (Chair). The epidemiology of dry eye disease: report of the epidemiology subcommittee of the international dry eye workshop. Oc Surf 2007 93-107.

4. Schein OD, Tielsch JM, Muñoz B, Bandeen-Roche K, West SK. Relationship between signs and symptoms of dry eye in the elderly: a population based perspective. Ophthalmol 1998105 1114-1119.

5. Guillon M, Maissa C. Dry eye symptomology of soft contact lens wearers and non-wearers. Optom Vis Sci 200582 829-834.

6. Hay EM, Pae TB, Hajeer A, Chambers H, Silman AJ. Weak association between subjective symptoms of and objective testing for dry eye and dry mouth: results from a population based study. Ann Rheum Dis 199857 20-24.

7. Begley CC, Chalmers RL, Abetz L, Venkataraman K, Mertzanis P, Caffery BA, Snyder C, Edrington T, Nelson $\mathrm{D}$, Simpson T. The relationship between habitual patientreported symptoms and clinical signs among patients with dry eye of varying severity. Inv Ophthalmol Vis Sci 200344 4753-4761

8. Moss SE, Klein R, Klein BEK. Prevalence of and risk factors for dry eye syndrome. Arch Ophthalmol 2000118 1264-1269.
9. Mertzanis P, Abetz L, Rajagopalan K, Espindle D, Chalmers R, Snyder C, Caffery B, Edrington T, Simpson T, Nelson JD, Begley C. The relative burden of dry eye in patients lives: comparisons to a US normative sample. Inv Ophthalmol Vis Sci 200546 46-50.

10. Miljanović B, Dana R, Sullivan DA, Schaumberg DA. Impact of dry eye syndrome on vision related quality of life. Am J Ophthalmol 2007143 409-415.

11. Nicholls JJ, Mitchell L, Nichols KK. An assessment of selfreported disease classification in epidemiological studies of dry eye. Inv Ophthalmol Vis Sci 200445 3453-3457.

12. Lemp MA. Advances in understanding and managing dry eye disease. Am J Ophthalmol 2008146 350-356.

13. Nichols JJ, Ziegler C, Mitchell CTL, Nichols KK. Selfreported dry eye disease across refractive modalities. Inv Ophthalmol Vis Sci 200546 1911-1914.

14. Bandeen-Roche K, Muñoz B, Teilsch JM, West SK, Schein OD. Self-reported assessment of dry eye in a population based setting. Inv Ophthalmol Vis Sci 199738 2469-2475.

15. Doughty MJ, Fonn D, Richter D, Simpson T, Caffery B, Gordon K. A patient questionnaire approach to estimating the prevalence of dry eye symptoms in patients presenting to optometric practices across Canada. Optom Vis Sci 1997 74 624-637.

16. Ellwein LB, Urato CJ. Use of dry eye care and associated changes among the Medicare population: 1991-1998. Arch Ophthalmol 2002120 804-811.

17. Schein OD, Muñoz B, Tielsch JM, Bandeen-Roche K, West SK. Prevalence of dry eye among the elderly. Am J Ophthalmol 1997124 723-728.

18. Simmons PA, Vehige JG, Carlisle C, Felix C. Comparison of dry eye signs in self-described mild and moderate patients. Inv Ophthalmol Vis Sci 200344 e-abstract 2448.

19. Narayanan S, Miller R, Prager TC, Jackson JA, Leach NE, McDermott AM, Christenson MT, Bergmanson JPC. The diagnosis and characteristics of moderate dry eye in noncontact lens wearers. Eye Contact Lens 200531 96-104.

20. Gulati A, Sullivan R, Buring JE, Sullivan DH, Dana R, Schaumberg DA. Validation and repeatability of a short questionnaire for dry eye syndrome. Am J Ophthalmol 2006142 125-131.

21. Johnson ME, Murphy PJ. Measurement of ocular surface irritation on a linear interval scale with the ocular comfort index. Inv Ophthalmol Vis Sci 200748 4451-4458.

22. Walt JG, Rowe MM, Stern KL. Evaluating the functional impact of dry eye: the Ocular Surface Disease Index (abstract). Drug Inf J 1997311436.

23. Schiffman RM, Christianson MD, Jacobsen G, Hirsch JD, Reis BL. Reliability and validity of the ocular surface disease index. Arch Ophthalmol 2000118 615-621.

24. Ozcura F, Aydin S, Helvaci MR. Ocular surface disease index for the diagnosis of dry eye syndrome. Oc Immun Inflamm 200715 389-393.

25. Snyman J (editor). Mims Desk Reference 432008.

26. McMonnies CW. Incomplete blinking: exposure keratopathy, lid-wiper epitheliopathy, dry eye, refractive surgery and dry contact lenses. Contact Lens Ant Eye 200730 37-51. 